University of Nebraska - Lincoln

DigitalCommons@University of Nebraska - Lincoln

Faculty Publications in the Biological Sciences

Papers in the Biological Sciences

2019

Gravid Tetragnathid Spiders Show an Increased Functional Response

\author{
Mary E. Boswell \\ University of Nebraska - Lincoln, mary@theboswells.org \\ John P. DeLong \\ University of Nebraska - Lincoln, jpdelong@unl.edu
}

Follow this and additional works at: https://digitalcommons.unl.edu/bioscifacpub

Part of the Biology Commons, Other Animal Sciences Commons, and the Terrestrial and Aquatic Ecology Commons

Boswell, Mary E. and DeLong, John P., "Gravid Tetragnathid Spiders Show an Increased Functional Response" (2019). Faculty Publications in the Biological Sciences. 824.

https://digitalcommons.unl.edu/bioscifacpub/824

This Article is brought to you for free and open access by the Papers in the Biological Sciences at DigitalCommons@University of Nebraska - Lincoln. It has been accepted for inclusion in Faculty Publications in the Biological Sciences by an authorized administrator of DigitalCommons@University of Nebraska - Lincoln. 
Boswell and DeLong in Food Webs (2019) 21: e00122.

Copyright 2019, Elsevier. Used by permission.

\title{
Gravid Tetragnathid Spiders Show an Increased Functional Response [Short communication]
}

\author{
Mary E. Boswell and John P. DeLong
}

\begin{abstract}
Spiders in the genus Tetragnatha feed on emerging aquatic insects, including mosquitoes and midges, but there is little known about the foraging behavior of these spiders. We hypothesized that female spiders actively developing egg sacs would increase food consumption to provide more energy to produce and provision their eggs. We tested this hypothesis by measuring foraging rates of Tetragnatha spiders kept in jars and provisioned with different levels of midges. We then tested for a difference in the functional response of spiders that did or did not lay egg sacs in their jars. Egg-laying and non-egg-laying spiders showed significantly different functional responses, indicating that Tetragnatha spiders can change their behavior or web structure to increase their foraging rate, presumably to accommodate increased energy demand for reproduction.
\end{abstract}

\section{Keywords: Foraging, Prey selection, Spider webs, Energy needs, Tetragnatha, Midges}

Predator-prey interactions are crucial to our understanding of ecological systems. Predation plays a key role in energy and nutrient movement through food webs, directly affecting the abundance of prey species (Pimm et al., 1991), the structure of food webs (Schmitz et al., 1997), and the functioning of ecosystems (Schmitz, 2008). Globally, spiders play an outsized role as predators of invertebrates, contributing both to the control of insect pests and the overall structure of terrestrial food webs (Nyffeler and Birkhofer, 2017). Thus, understanding sources of variation in spider foraging is critical to understanding the structure and function of terrestrial food webs.

The functional response, or foraging rate with respect to prey density, provides a standardized way of assessing variation in foraging rates. The functional response typically is written as a saturating, type II function using the 'disc' equation:

$y=\frac{a x}{1+a h x}$

where $a$ is the space clearance rate of the predator, $h$ is the handling time for one prey item, $x$ is the number of prey items available, and $y$ is the per capita rate of prey consumption (Holling, 1959). The handling time and space clearance rate of a predator are affected by several factors, including the body size of the predator and the prey, the body condition of the predator, temperature, and the predator's foraging strategy (Lyon et al., 2018; Pawar et al., 2012; Rall et al., 2011; Uiterwaal et al., 2017). Foraging strategy may be a fixed aspect of a predator's behavior, such as sit-and-wait versus active pursuit predation, but foraging behaviors also may be influenced by the energetic needs of the organism. Some organisms, for example, increase their food intake (hyperphagy) in preparation for energy-intensive activities such as migration (Odum, 1960) or reproduction (Gurney and Nisbet, 2004). Higher foraging rates and diet quality are also correlated with increased quality of egg production in arachnids (Rahman et al., 2012; Wil- der and Rypstra, 2008). It is less clear, however, whether sitand-wait predators can increase prey intake in response to the increased energy demand associated with reproduction.

Long-jawed orb-weavers vary foraging strategies in response to prey density and type (Gillespie and Caraco, 1987; Tahir et al., 2009; Yoshida, 1987). In particular, Tetragnatha spiders may adjust their foraging location in response to prey density (Gillespie and Caraco, 1987), presumably with the outcome of increasing prey capture. Such differences in foraging behavior should translate to a steeper functional response with either a greater space clearance rate, lower handling time, or both, for those individuals with higher energy demands, but this hypothesis has not been tested.

We compared the functional response of wild-caught female Tetragnatha laboriosa spiders that did and did not lay eggs while they were kept in the lab. While previous studies have controlled for the ef-fects of gravidity on foraging rates by using only gravid females, we sought to use both gravid and non-gravid females to compare the two (Ali et al., 2011; Rahman et al., 2012). We hypothesized that female spiders that had laid egg sacs in their containers would show a steeper functional response (greater rates of foraging at all prey densities) than those that did not, since higher consumption rates are presumably needed to produce and provision the eggs.

We conducted our experiment during June of 2017 and 2018 on the south shore of Lake Ogallala, Nebraska, at Cedar Point Biological Station. We collected Tetragnatha spiders in the morning by sweep-netting grassy roadsides and meadows. Each spider was individually housed in a cylindrical 250 $\mathrm{mL}$ plastic jar, with a height of $7.5 \mathrm{~cm}$ and diameter of $6.5 \mathrm{~cm}$. We placed a damp piece of paper towel in each jar to provide moisture and rewetted them as needed to maintain moisture. We left the spiders alone during the day to allow time for each spider to settle and build its web. We assumed that all spiders were female, since male Tetragnatha spiders do not build webs. We collected a pre-determined random number of midges (Chironomidae) directly into the spider habitats from the windows of the Cedar Point Biological Station lab after sunset using a jar lid fitted with an aspirator. We chose midges

Boswell: School of Natural Resources, mary@theboswells.org (corresponding author)

DeLong: School of Biological Sciences, jpdelong@unl.edu

University of Nebraska-Lincoln, Nebraska, USA 


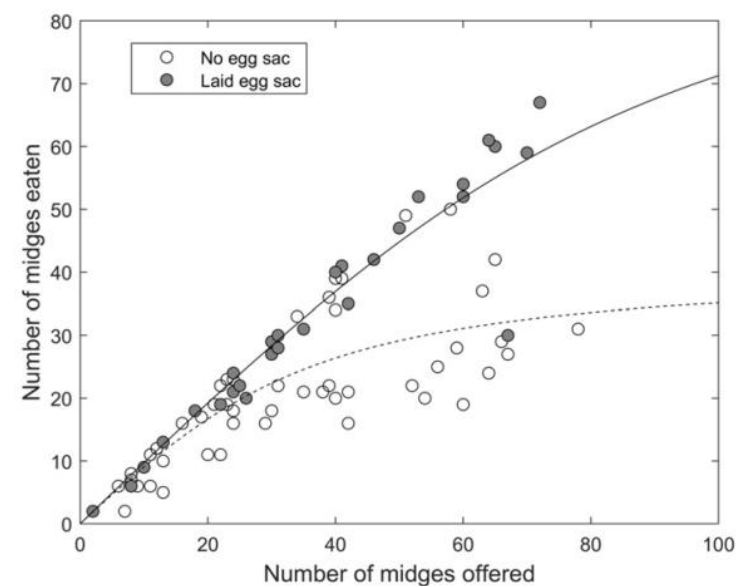

Figure 1. The functional response of Tetragnatha spiders foraging on midges. Spiders that laid eggs had a steeper functional response with a higher asymptote than spiders that did not.

as prey because they make up the bulk of Tetragnathid spiders' diets (Yoshida, 1987) and are a dominant aerial insect in the area. We left spiders to hunt overnight for 10 hours, and at 7:30 A.M. the following morning, we counted the uneaten midges to determine the number of midges that were eaten. Throughout the experiment, several of the spi-ders laid egg sacs in their containers. We waited 3-4 days after the foraging trial ended to allow gravid spiders to lay egg sacs. We took care to not damage the egg sacs while changing lids and remoistening the jars. Temperature in the lab was approximately $21^{\circ} \mathrm{C}$.

We did not replace prey as they were eaten through the night, and therefore the prey density within the jars declined with each prey capture. We therefore fit our data to the Rogers random predator equation, which accounts for this within-experiment prey depletion (Bolker, 2008; Rogers, 1972), where

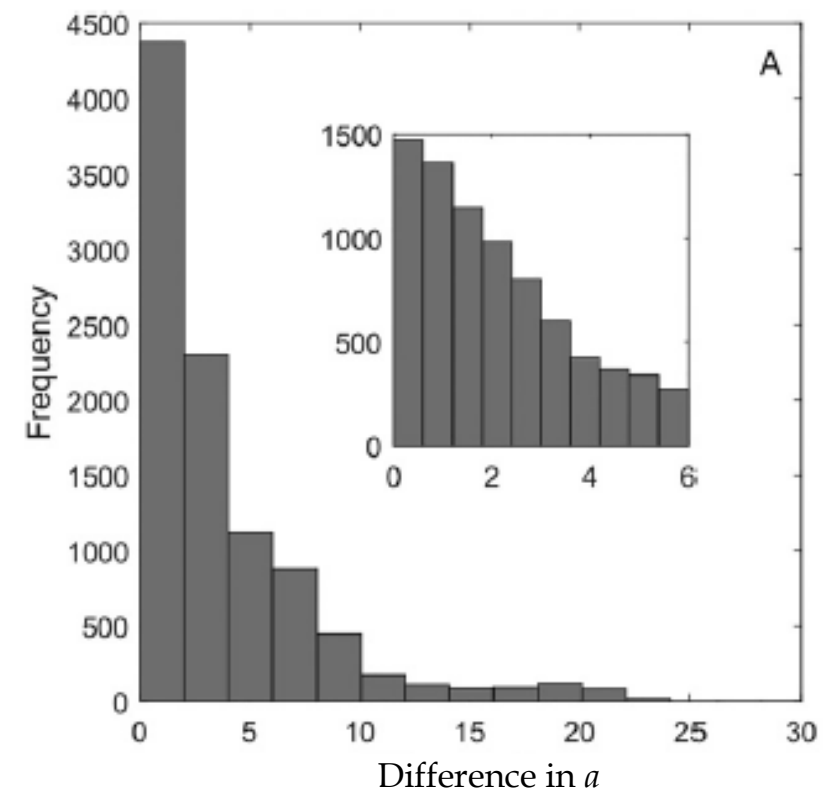

parameters are the same as in Equation (1) and $W$ is the Lambert $W$ function:

$\mathrm{y}=\mathrm{x}-\frac{W(\mathrm{ahx} \exp (-\mathrm{a}(0.42-\mathrm{hx})))}{\mathrm{ah}}$

We used ordinary non-linear least squares regression to estimate the mean and $95 \%$ confidence intervals of the parameters of Equation (2) (space clearance rate $a$ and handling time $h$ ). We fit the data for egg-laying and non-egg-laying spiders separately. We used a bootstrap approach to determine if $a$ and $h$ were significantly different between egg-sac-laying and non-egg-sac-laying spiders. We randomly sampled with replacement each original data set to create 100 bootstrapped datasets, and we fit Equation (2) to each dataset. We then calculated the difference between the parameters for each possible pair of curves that differed in egg-laying status. This process generated a distribution of differences between the two parameters, and we assessed significant differences between the parameters by determining whether the $95 \%$ confidence interval of the difference between parameters included zero.

Egg-sac-laying and non-egg-sac-laying spiders each showed Type II functional responses (Figure 1; alaying $=8.14$ arenas per predator per day, $95 \%$ CIs: 5.67 to 27.54 ; $\mathrm{h}_{\text {laying }}=$ 0.003 days, $95 \%$ CIs: $\sim 0.00$ to $0.008, \mathrm{R}^{2}=0.90 ;$ anon-laying $=7.53$ arenas per predator per day, $95 \%$ CIs: 4.57 to $15.72 ; \mathrm{h}_{\text {non-laying }}=$ 0.01 days, $95 \%$ CIs: 0.007 to $0.013, \mathrm{R}^{2}=0.65$ ). The confidence intervals for the differences in $a$ and $h$ between the two data sets did not include zero, so the two parameters were considered significantly different from each other, with $a$ being higher and $h$ lower for egg-sac-laying spiders (Figure 2; 95\% CIs difference in $a: 0.09$ to $21 ; 95 \%$ CIs difference in $h: 0.0016$ to 0.012 ).

Much of what we know about variation in the functional response comes from across-species comparisons (e.g. Uiterwaal and DeLong, 2018). There is clear variation in both

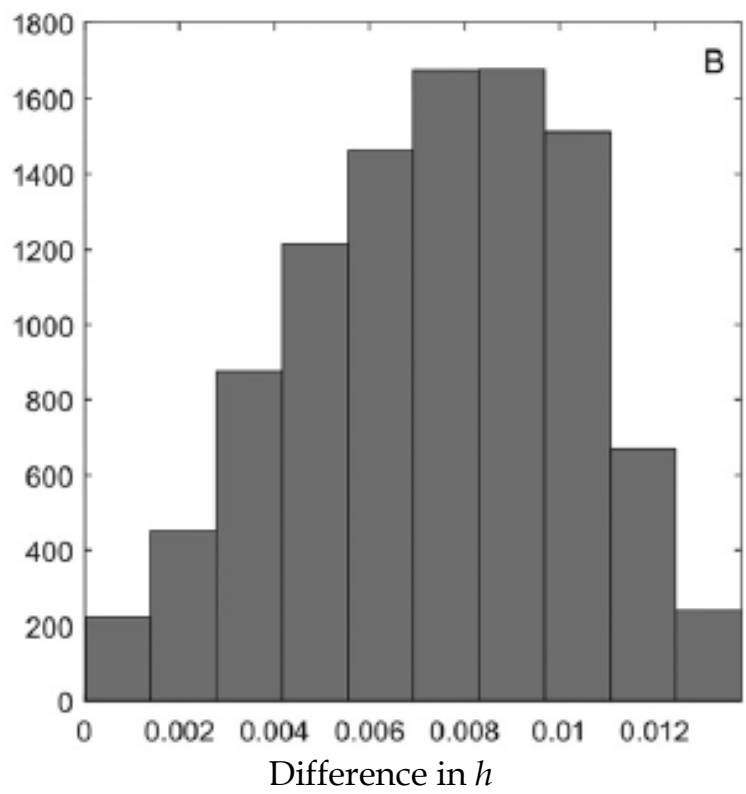

Figure 2. The distribution of differences between A) space clearance rate, $a$ and B) handling time, $h$. The $95 \%$ confidence intervals on these distributions did not include zero, indicating that both parameters were significantly different between egg-laying and nonegg-laying spiders. The leftmost bins include only positive differences. In A) the inset shows detail for the lower bins. 
space clearance rate and handling time across species associated with body mass, temperature, predator satiation, foraging dimensionality, and the taxonomic identity of both predator and prey (DeLong et al., 2015; Kalinoski and DeLong, 2016; Li et al., 2018; Pawar et al., 2012; Rall et al., 2011, 2008; Uiterwaal and DeLong, 2018). Additional variation in the functional responses within predator-prey pairs is associated with body mass, prey defenses, temperature, energetic history, and individual identity (Barnhisel and Kerfoot, 2004; Hammill et al., 2010; Lyon et al., 2018; Schrer et al., 2016; Spitze, 1985). However, it is less clear that particular energydemanding activities drive individual-variation in the functional response. Our experiment clarifies that the shift to being gravid increases both the steepness and height of the functional response in long-jawed orb-weavers. This shift could have implications for the strength of inter-actions linking these spiders to their prey and consequently for the predatorprey dynamics.

Tetragnatha spiders in this study that laid egg sacs ate more midges at all prey densities than those that did not. Although it was clear that there was not complete separation of foraging behavior between egg-sac-laying and nonlaying spiders, suggesting some possible miscategorization of individual spiders, our results show that reproductive status should be considered when determining the functional response of a predator, as individuals provisioning offspring need higher prey intake. How a sit-andwait predator achieves an increase in prey consumption, however, is not clear. The most likely candidate for the increased foraging is alterations to spider web structure. A previous study showed that starved Octonoba sybotides built webs with tighter spacing than usual, likely to target smaller but more numerous prey items (Watanabe, 2001). The egg-laying spiders in this experiment may have modified their webs in a similar manner to increase their intake of midges. More investigation into differences in web structure is necessary to determine how these sit-and-wait spiders are able to alter their prey consumption rate.

\section{Funding sources}

This research did not receive any specific grant from funding agencies in the public, commercial, or not-for-profit sectors.

\section{Declaration of competing interest}

None.

\section{References}

Ali, M., Naif, A.A., Huang, D., 2011. Prey consumption and functional response of a phytoseiid predator, Neoseiulus womersleyi, feeding on spider mite, Tetranychus macfarlanei. Journal of Insect Science 11, 167. https://doi.org/10.1093/jis/11.1.167.

Barnhisel, D.R., Kerfoot, W.C., 2004. Fitting into food webs: behavioral and functional response of young lake trout (Salvelinus namaycush) to an introduced prey, the spiny cladoceran (Bythotrephes cederstroemi). Journal of Great Lakes Research, Exploring Superior 30, 300-314. https:// doi.org/10.1016/S0380-1330(04)70393-7.

Bolker, B.M., 2008. Ecological Models and Data in R. Princeton University Press.

DeLong, J.P., Gilbert, B., Shurin, J.B., Savage, V.M., Barton, B.T., Clements, C.F., Dell, A.I., Greig, H.S., Harley, C.D.G., Kratina, P., McCann, K.S., Tunney, T.D., Vasseur, D.A., O'Connor, M.I., 2015. The body size dep- endence of trophic cascades. American Naturalist 185, 354366. https://doi.org/10.1086/679735.

Gillespie, R.G., Caraco, T., 1987. Risk-sensitive foraging strategies of two spider populations. Ecology 68, 887-899. https:// doi.org/10.2307/1938360.

Gurney, W.S.C., Nisbet, R.M., 2004. Resource allocation, hyperphagia and compensatory growth. Bulletin of Mathematical Biology 66, 1,731-1,753. https://doi.org/10.1016/j.bulm.2004.03.008.

Hammill, E., Petchey, O.L., Anholt, B.R., 2010. Predator functional response changed by induced defenses in prey. American Naturalist 176, 723-731. https://doi.org/10.1086/657040.

Holling, C.S., 1959. Some characteristics of simple types of predation and parasitism. Canadian Entomologist 91, 385398. https:// doi.org/10.4039/Ent91385-7.

Kalinoski, R.M., DeLong, J.P., 2016. Beyond body mass: how prey traits improve predictions of functional response parameters. Oecologia 180, 543-550. https:// doi.org/10.1007/s00442-015-3487-z.

Lesar, C.D., Unzicker, J.D., 1978. Life history, habits, and prey preferences of Tetragnatha laboriosa (Araneae: Tetragnathidae). Environmental Entomology 7, 879-884. https://doi.org/10.1093/ee/7.6.879.

Li, Y., Rall, B.C., Kalinkat, G., 2018. Experimental duration and predator satiation levels systematically affect functional response parameters. Oikos 127, 590-598. https:// doi.org/10.1111/oik.04479.

Lyon, S.R., Sjulin, C.A., Sullivan, K.M., DeLong, J.P., 2018. Condition-dependent foraging in the wolf spider Hogna baltimoriana. Food Webs 14, 5-8. https://doi.org/10.1016/j.fooweb.2017.12.003.

Nyffeler, M., Birkhofer, K., 2017. An estimated 400-800 million tons of prey are annually killed by the global spider community. Science of Nature 104, 30. https://doi.org/10.1007/s00114-017-1440-1.

Odum, E.P., 1960. Premigratory hyperphagia in birds. American Journal of Clinical Nutrition 8, 621-629. https://doi.org/10.1093/ajcn/8.5.621.

Pawar, S., Dell, A.I., Savage, Van M., 2012. Dimensionality of consumer search space drives trophic interaction strengths. Nature $486,485-489$. https://doi.org/10.1038/nature11131.

Pimm, S.L., Lawton, J.H., Cohen, J.E., 1991. Food web patterns and their consequences. Nature 350, 669. https:// doi.org/10.1038/350669a0.

Rahman, V.J., Babu, A., Roobakkumar, A., Perumalsamy, K., 2012. Functional and numerical responses of the predatory mite, Neoseiulus longispinosus, to the red spider mite, Oligonychus coffeae, infesting tea. Journal of Insect Science 12, 1-12. https://doi.org/10.1673/031.012.12501.

Rall, B.C., Guill, C., Brose, U., 2008. Food-web connectance and predator interference dampen the paradox of enrichment. Oikos 117, 202-213. https://doi.org/10.1111/j.2007.0030-1299.15491.x.

Rall, B.C., Kalinkat, G., Ott, D., Vucic-Pestic, O., Brose, U., 2011. Taxonomic versus allometric constraints on non-linear interaction strengths. Oikos 120, 483-492. https://doi.org/10.1111/j.1600-0706.2010.18860.x.

Rogers, D., 1972. Random search and insect population models. Journal of Animal Ecology 41, 369-383. https:// doi.org/10.2307/3474. 
Schmitz, O.J., 2008. Effects of predator hunting mode on grassland ecosystem function. Science 319, 952-954. https://doi.org/10.1126/science.1152355.

Schmitz, O.J., Beckerman, A.P., O’Brien, K.M., 1997. Behaviorally mediated trophic cas-cades: effects of predation risk on food web interactions. Ecology 78, 1,388-1,399. https:// doi.org/10.1890/0012-

9658(1997)078[1388:BMTCEO]2.0.CO;2.

Schröder, A., Kalinkat, G., Arlinghaus, R., 2016. Individual variation in functional response parameters is explained by body size but not by behavioural types in a poeciliid fish. Oecologia 182, 1129-1140. https://doi.org/10.1007/s00442016-3701-7.

Spitze, K., 1985. Functional response of an ambush predator: Chaoborus americanus predation on Daphnia pulex. Ecology 66, 938-949. https:// doi.org/10.2307/1940556.

Tahir, H.M., Butt, A., Sherawat, S.M., 2009. Foraging strategies and diet composition of two orb web spiders in rice ecosystems. Journal of Arachnology 37, 357-362. https://doi.org/10.1636/P08-89.1.
Uiterwaal, S.F., DeLong, J.P., 2018. Multiple factors, including arena size, shape the functional responses of ladybird beetles. Journal of Applied Ecology 55, 2,429-2,438. https://doi.org/10.1111/1365-2664.13159.

Uiterwaal, S.F., Mares, C., DeLong, J.P., 2017. Body size, body size ratio, and prey type influence the functional response of damselfly nymphs. Oecologia 185, 339-346. https://doi.org/10.1007/s00442-017-3963-8.

Watanabe, T., 2001. Effects of web design on the prey capture efficiency of the uloborid spider Octonoba sybotides under abundant and limited prey conditions. Zoological Science 18, 585-590. https://doi.org/10.2108/zsj.18.585.

Wilder, S.M., Rypstra, A.L., 2008. Diet quality affects mating behaviour and egg production in a wolf spider. Animal Behaviour 76, 439-445. https://doi.org/10.1016/j.anbehav.2008.01.023.

Yoshida, M., 1987. Predatory behavior of Tetragnatha praedonia (Araneae: Tetragnathidae). Acta Arachnologica 35, 57-75. https://doi.org/10.2476/asjaa.35.57. 